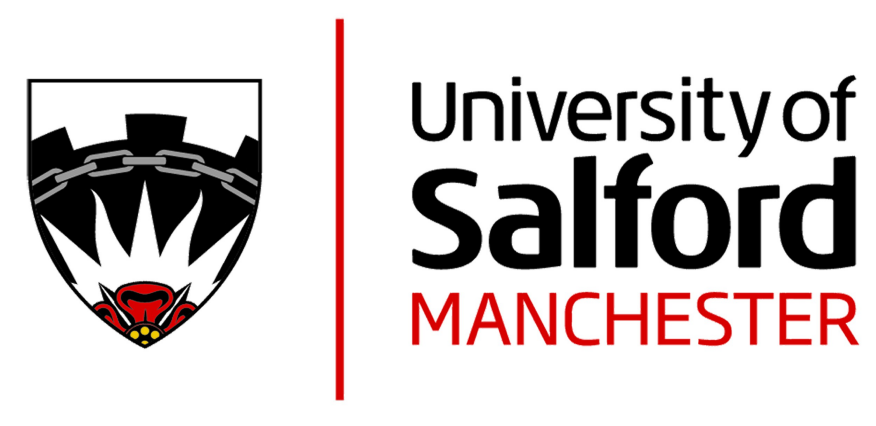

\title{
The Perceived Psychological Responsibilities of a Strength and Conditioning Coach
}

\author{
Radcliffe, Jon N., Comfort, P and Fawcett, Tom \\ http://dx.doi.org/10.1519/JSC.0000000000001656
}

\begin{tabular}{|l|l|}
\hline Title & $\begin{array}{l}\text { The Perceived Psychological Responsibilities of a Strength and } \\
\text { Conditioning Coach }\end{array}$ \\
\hline Authors & Radcliffe, Jon N., Comfort, P and Fawcett, Tom \\
\hline Type & Article \\
\hline URL & This version is available at: http://usir.salford.ac.uk/id/eprint/50494/ \\
\hline Published Date & 2018 \\
\hline
\end{tabular}

USIR is a digital collection of the research output of the University of Salford. Where copyright permits, full text material held in the repository is made freely available online and can be read, downloaded and copied for non-commercial private study or research purposes. Please check the manuscript for any further copyright restrictions.

For more information, including our policy and submission procedure, please contact the Repository Team at: $\underline{\text { usir@ } @ \text { salford.ac.uk. }}$ 


\section{ABSTRACT}

2 Research is limited in exploring the specific psychology oriented responsibilities of the

3 strength and conditioning professional. The present research explored the psychological 4 responsibilities adopted by accredited strength and conditioning coaches. Participants 5 comprised 10 participants working within the UK, 3 within the USA and 5 within Australia 6 offering a cross section of experience from raging sport disciplines and educational 7 backgrounds. Participants were interviewed either in person or via Skype. Thematic 8 clustering was employed utilizing interpretative phonological analysis to identify common 9 themes. Over half $(61 \%)$ of the respondents reported that their position as a strength and 10 conditioning coach required additional psychology orientated responsibilities. These 11 comprised a counselling role in the absence of psychologist the use of 'softer skills' in a 12 mentoring role of the athlete during a challenging situation. The coach could play an 13 influential role in shaping the mentality of the team. The coach identifies how the role results 14 in working to relay information for the athlete to other support staff and similarly from the support staff through the athlete. The coach identifies how the role results in working to relay information for the athlete to other support staff and similarly from the support staff to the athlete. In addition to identifying the resonant psychological orientated responsibilities discussion is made with specific focus on the ethical boundary to which strength and conditioning coaches must reside regarding the competencies to provide psychological support.

\section{KEY WORDS}

CPD; Counselling; Mentoring; Ethics; Professional practice; Performance enhancement. 


\section{INTRODUCTION}

26 The role of the strength and conditioning practitioner is an increasingly complex one. The 27 role comprises various responsibilities ranging from, technical instruction, adopting suitable 28 advanced training methods, through to logistics and organization (29-31). A tremendous body 29 of work exists examining the optimization of training practices regarding the promotion of 30 physiological adaptation to enhance performance however there is a stark contrast between investigations concerning physiological and technical subject areas and the specific role of the strength and conditioning coach.

Previously, quantitative research has proved useful in identifying the frequency in to which practitioners are utilizing particular psychological strategies with strategies such as goal setting being used considerably more than more complex cognitive interventions such as mental imagery (38). However, whilst encouraging with regard to the implementation of such interventions, the quantitative nature did not afford the expansion to examine reasons accounting for such a discrepancy aside from professional experience. More recently

40 Radcliffe et al. (39) employed a qualitative approach to identify the specific psychological interventions used within strength and conditioning practice by strength and conditioning specialists. This work is effective in identifying the specific interventions and techniques employed, specifically focusing on psycho-physiological regulatory techniques and strategies to enhance confidence and mirrored the recommendations made by Mellalieu and Shearer (33). However, aside from identifying the use of specific psychological interventions such research does little to explore the complexities associated with the psychological responsibilities of the strength and conditioning specialist. Such an exploration is pertinent when considering the evolving role requirements and complexities associated with working as a strength and conditioning coach (40). 
51 Contemporary work has explored the responsibilities of the practicing strength and conditioning specialist in observing the development of role responsibilities as practitioners' progress through their careers (46) whereby various roles and responsibilities are adopted such as managing stakeholder expectation and being receptive to athletes sharing sensitive information (46). The perceived evolving role further signaling the complexities of the discipline relating to interpersonal skills. Furthermore, it is suggested that as a helping profession strength and conditioning practitioners should use more "softer-skills" appreciating the requirement for interpersonal skills in fostering an effective clientpractitioner relationship (46). Such softer-skills have previously been defined as gaining trust, and ensuring athlete buy-in justifying approaches to practice (46).

Given the evolving role of the strength and conditioning specialist it is reassuring that the academic community has sought to define the role of the strength and conditioning specialist. However, exploratory studies have typically focused upon the daily role responsibilities and working environments whilst the specific psychological responsibilities are often regarded as miscellaneous within the strength and conditioning specialist repertoire, if reported at all (10, 13-15, 30, 40). As a result, notwithstanding the need for the aforementioned "softer skills" (46), little is known regarding the specific psychology-related responsibilities of the strength and conditioning specialist. Additional uncertainty exists regarding the precise psychological responsibilities of the strength and conditioning professional as only the criteria for the Certified Strength and Conditioning Specialist exam states the requirement of "psychological skills to enhance training and/or performance of the athlete" (34) whilst other pathways to recognized certification fail to clarify of the role of psychology within applied strength and 
74 conditioning work. Consequently a role analysis focusing on the coaches' perception of psychological responsibilities is warranted.

Academic interest in the perceptions of various disciplines towards psychology has focused on quantitative research methods such as survey design $(2-4,16,20,23,35)$ with few studies using qualitative methods such as semi-structured interviews $(3,9,11)$. The discrepancy in the volume of published work and between qualitative and quantitative research is surprising given that qualitative research explores in-depth and underlying perceptions towards psychology and would serve to provide an explanation of the rationale for including psychological strategies and provide insight into complexities inaccessible via quantitative methods. To date, qualitative research specifically examining psychology use within strength and conditioning has employed predominantly observational methods, specifically focusing on coach behavior $(17,29)$. Such observational studies provide little insight into the specific psychological interventions, the rationale behind them, and improtantly the perceptions of the practitioners themselves. Recent work (39) identified the types of interventions and the main aims of employing such strategies used however failed to highlight the perceptions of the strength and conditioning specialists' regarding their perceived responsibilities relating to the inclusion of psychological strategies within applied practice.

Therefore, in line with the suggestion that the research can serve as a foundation to improve the profession and more research is required (29), the aim of the present work is to adopt an interpretive phenomenological approach (43) to explore strength and conditioning practitioners' personal experiences of using psychology within applied practice to ascertain the perceived psychology related role requirements of the discipline. It is hypothesized that 
strength and conditioning specialists would possess a range of client centered and softer skills which have often been overlooked within the existing research base.

\section{METHOD}

\section{Experimental approach to the problem}

To explore the practitioners' understanding at a deeper level, a interpretive phenomenological approach was used to examine the roles which may be implicit within the narratives and omitted using different methodological approaches such as content analysis. Thus the use of Interpretive Phenomenological Analysis (IPA) permits the exploration of the subjects worldview (36) thus perceptions will be captured from the data despite not being explicitly stated (36) and would be a suitable approach to gain insight from the perspective of individual practitioners. Such an approach has previously been successfully used to examine the perceptions of physiotherapists towards psychology exploring real life experiences of applying psychological interventions (3). Furthermore the use of interpretive phenomenological analysis is well suited to the current research questions owing to the notion that many responsibilities acquired via the lived experience of the practitioner.

In order to answer the aims of the current research question an approach was adopted where by each individual case is examined in detail prior to the amalgamation of key concepts resonant across the sample. The approach utilizes semi-structured interviews, transcribed verbatim, which were analyzed for key resonant themes using IPA (41). Semi-structured interviews aim to explore a series of topics whilst not constrained to the order in which questions are asked. This approach lacks the comparability and consistency of the structured interview method however this approach allows for the creation of a fluid narrative enabling the disclosure 
122 of a variety of topics. Indeed such an approach is considered the exemplary data collection

123 method aligned with IPA (37). Such a design is applicable when examining topics centered on

124 lived experiences where standardized research instruments may prevent the collection of

125 relevant data (46). Furthermore as stated by Tod et al. (46) the use of qualitative methods

126 employing semi-structured interviews have proven successful in answering psychology

127 orientated research questions within strength and conditioning.

\section{Ethical approval}

130 Before commencing the study, the Institutional Review Board provided ethical approval for 131 the experimental procedures. Prior to participation all subjects received an invitation email 132 containing including a clear explanation of the potential benefits and risks associated with the

133 research, how the data will be handled, the dissemination of findings, and voluntary nature of

134 the study. An email contact was provided for the lead investigator should any potential 135 applicants request additional information.

\section{Subjects}

138 Eighteen participants were recruited for interview. The present study employed convenience sampling drawn from a previously obtained sample pool initially compiled through purposive

140 sampling (38). Additional snowball sampling was used as it is regarded as an effective

141 method to enlist potential participants and compatible with the concept of purposive 142 sampling. Participants comprised 17 males and one female. Of these participants, 10

143 participants were working within the UK, 3 within the USA and 5 within Australia. Each was 144 accredited by the National Strength and Conditioning Association, the United Kingdom

145 Strength and Conditioning Association, the Australian Strength and Conditioning 146 Association, or held a combination of dual accreditation. The participants provided a cross 
147 section of experience working as strength and conditioning practitioners, ranging from two

148 years to over 20 years within various sport disciplines. All participants had experience

149 working at a minimum of national level.

150

151 Procedure

152 Interviews were conducted at a mutually-agreed time and location with specific consideration

153 of time zone differences and typically lasted between 40-80 minutes. Interviews were

154 conducted face-to-face either in person or via video calls to prevent the location of the subject

155 becoming barrier to data collection. Data was recorded using a digital voice recorder

156 (Olympus, VN-5500PC), and transcribed verbatim. Interviews were conducted over the

157 period commencing October 2011 to January 2012.

158

159 The semi-structured interview schedule was composed and scrutinized by specialists from the

160 disciplines of psychology and strength and conditioning for content validity. The questions

161 explored the individuals' narrative of their experience being a strength and conditioning

162 coach with particular focus on the interactions between practitioner and athlete. Examples of

163 the questions included were: 'Could you tell me about your experience as a strength and

164 conditioner?'; 'What would you describe as the main purpose of psychology within Strength

165 and Conditioning?'; 'Do you include mental strategies in your training?'; 'Do you feel

166 psychological support is effective to your athletes?'. The questioning was open-ended to

167 allow elaboration around personal professional development and to promote the narrative of 168 the subject. 


\section{Analysis}

170 The analysis employed IPA following the recommendations of Smith (42) and was conducted

171 with NVivo 9 assistive software (QSR International Pty Ltd., Victoria, Australia) to identify

172 common themes.

173

174 The lead author transcribed all interviews verbatim. Adhering to IPA guidelines the transcripts were read sufficiently to provide an in-depth familiarization with the data and specific context of the data. Considering specific questions, each transcript was analyzed to

177 highlight specific instances within the participants' accounts. During first stage analysis, 178 Nvivo 9 assistive software (QSR International Pty Ltd., Victoria, Australia) was used to 179 extract pertinent notes from the narratives. Notes were then compiled to form thematic emergences after which the themes were reviewed for confirmation of understanding within

181 the contexts outlined during the narrative. This procedure was repeated for the remaining 182 transcripts with the application of an evolving 'master template' guided through emerging 183 themes used to focus the analysis (3).

184 Commonalities were explored between transcripts which resulted in the development of higher order themes with appropriate supporting quotes identified. In instances where quotes failed to sufficiently evidence themes the theme was removed from analysis (3).

\section{Validity and Reliability}

189 To increase the likelihood of credible finding is triangulation was used. Triangulation

190 concerns the verification of results by the use of different researchers, different methods, or

191 different sources. In endeavouring to provide triangulation of sources, participant groups

192 were recruited from ranging international settings for instance the UK, the USA and

193 Australia. Thus data source triangulation was performed by which information obtained from 
194 participants from differing cultural and professional backgrounds evidences the extent to

195 which similar thematic emergences occurred across different backgrounds (46). Audience

196 triangulation was used in which an experienced qualitative investigator reviewed selected

197 quotes to ensure all relevant themes were exposed and to prevent experiment bias (46).

198

199 Member checking involves presenting raw data to the participants to validate the accurate 200 collection of data. Member checking, regarded as the most important method in the 201 demonstration of credible findings (25), can be progressed in elevating levels of detail 202 ranging from confirmation of raw text to presenting the participants with the interpretation of 203 findings. The present study used member checking to validate the raw text and the 204 presentation of particular thematic emergences. Responses confirmed the accuracy or the data 205 collection and was in agreement with the major thematic emergences.

207 Dependability is the ability of the findings to be repeated and consistent, confirmability is the 208 degree to which the research findings are unbiased and attributable to the research 209 participants. The research audit is regarded as the prime method of demonstrating both 210 confirmability and dependability (25). The research has adhered to consistent methodological 211 constraints as agreed to and governed by the Institutional Research Ethics panel, this ensured

212 that the method can be attributed to the research outcome and thus the procedure can be 213 repeated. 


\section{RESULTS}

220 Notwithstanding the logistical and physical training tasks, the psychological responsibilities

221 of the strength and conditioning professional demonstrated the ranging and complex nature of 222 the role. Over half $(61 \%)$ of the respondents reported that their position as a strength and 223 conditioning professional required additional psychology-orientated responsibilities. A 224 variety of roles emerged within the narratives. Such responsibilities were thematically grouped into four main themes of providing emotional support; providing sport psychology support; shaping team dynamics; and facilitating communication with athletes and key support staff (Figure 1). Each of the resonant emergent roles pertinent to the discipline of psychology will be addressed in turn in the subsequent results section.

INSERT FIGURE 1 HERE

\section{Provide emotional support}

232 It was apparent that the strength and conditioning professionals believed that they fulfilled a counselling role through which they would provide emotional support to the athletes that they worked with. Three experienced coaches documented the perception that the strength and conditioning coach can provide emotional support:

"Sometimes they can get so focused on just one thing, their performance, they forget that they are human beings and they have got a whole life and sometimes I just make them realize you know what ok you have messed up there but get the whole picture of what you are doing."

240 The practitioner believed that they have a role that extends beyond the physical training of the athlete and that they can take responsibility of the psychological well-being of the athlete with regard to other aspects of the athlete's life. Such a notion aligns with the concept of developing soft skills (46) and that the strength and conditioning coach perceived their role to

244 extend to providing emotional support to athletes. 
"Some of them come and they start crying because they have got no one else to talk to. You need to be able to relate and understand [and] be compassionate to that person to make them understand that it is not all about that. Be almost a counsellor, that's really important."

There is indication that a counsellor is a specific role, however the strength and conditioning coach believed their behaviors could be viewed as counselling. This again mirrors the work of Tod et al. (46) which suggests that with experience the strength and conditioning coach adopts a supporting role with athletes seeking an individual with whom to share sensitive information.

"Probably I am here. Because you always get the athletes that don't make the England squad and they ring you up and you have to say something so yeah they'll come to you with it."

It is also evident that in some cases this is a reluctant role whereby the practitioner feels that they have to say something rather than want to. It is likely that such confidence in fulfilling the role is aligned with the experience of the strength and conditioning coach. As has been previously stated the ability to provide an informal counselling service is governed by the experience of the coach (46). It is possible that the strength and conditioning training environment serves to enable the athlete to disassociate away from stressful situations and consequently the environment itself may be conducive to the strength and conditioning coach being perceived to be able to offer emotional support.

"I am fed up I just split up with my boyfriend" and in situations like that normally what I say is that any outside stressor like that, athletics is a really interesting side issue for stress, because the minute you step the over the door to the weight room, set your foot inside of the circle that is you time. That is something you can do for you. Nobody else can influence that, just you, so spend that hour bettering you, forget it, and leave it out the door."

It is clear that the perceptions of the strength and conditioning coaches are different. It is evident that there is the adopted responsibility of providing emotional support which is often unrelated to strength and conditioning; however there is a lack of evidence to support the 
notion that practitioners are providing a true counselling service and a misperception of counselling practice is evident.

Two coaches recall instances in which they have adopted 'softer skills' in a mentoring role of the athlete during a challenging situation.

"Got a young footballer, she's a cracking kid. She's playing in a team where there is a seasoned international; a world class player, so I sat down with her and was like where am I going with this, what am I trying to do? She was like I am not going to get in the team because this person is ahead of me so I tried to build her ego up a bit and make her feel a lot better about herself and get her to think about the positives in her performance."

It is clear that the strength and conditioning practitioner is occasionally afforded the opportunity to work with players away from the team environment. There is the notion that by working in an environment removed from the team setting the practitioner is able to address athletes on an individual basis. Through such integrations the strength and conditioning specialist offers a supportive role in addition to the physical preparation of the athlete in which the support is often grounded on the coaches own previous experiences.

"I wouldn't say there is anything ground breaking in that just literally have a conversation in that trying to get their side of the story trying to put over some perspective from what my experience has been."

The practitioner adopts a mentoring approach; in relating their experiences to those of the athlete it is emphasizing the importance of two-way communication.

There is also indication of the value that practitioners can offer with the availability of the one-to-one training environment detached from the goals of the team coach.

"And I also give them a task of in training, and bearing in mind your sport specific coach wouldn't have this conversation with her because your sport specific coach is perhaps happy with the person who is on the team whereas I am just working with this individual so I am saying you need to get next to this person in training and do everything they do but better. And she has responded really well to that." 
304 Again, in this instance the perspective of the strength and conditioning coach is centered on

305 individual development. This suggests the instrumental role possessed by the strength and

306 conditioning coach in facilitating the progress of players who are perceived to be neglected

307 within the team setting. This implies the important motivational role of the strength and

308 conditioner adopting a mentoring position.

\section{Shape team dynamics}

310 One individual recited an occasion demonstrating that the strength and conditioning coach could play an influential role in shaping the mentality of the team.

"The beginning of the off season, an example was when I first got out to where I am at in January with volleyball it was my first interaction with the team was with weightlifting and what I actually decided to do was do circuit training for about two weeks. The circuit training was time-based and it was just one thing, onto the next, onto the next, and the big thing I stressed to the girls when I was there was that I am using this to see who is the leader, who is going rise up, and see who can push through hard times and stuff like that."

It is evident that beyond the physiological conditioning of the players the strength and

conditioning coach can create an environment through which team mentality can be shaped.

The coach sees the diverse role functions and it is evident that they want to have more responsibility for shaping and influencing team dynamics. A second individual recited an occasion when they were informed that it is the role of the strength coach to help shape team mentality.

"I know that it is important and now that I think about it I do remember talking to one of the head football strength coaches that I worked with and he mentioned to me that the role of the strength coach is also that mentality of the team how aggressive they are in the weight room and how that applies on the football field so I mean that might be something I want to keep in the back of my mind. I've always kept that in the back of my mind too."

331 It is therefore evident that the strength and conditioning coach is positioned to offer

332 individual support as well as the opportunity to foster a productive team environment.

333 However, this may suggest that the strength and conditioning specialist is crossing 
334 boundaries and addressing psychological strategies that are used during the competitive environment in addition to the strength and conditioning setting, again this indicates a level of role ambiguity in the psychological practices of the strength and conditioning coach.

\section{Receive and relay information}

Two practitioners stated that they fulfil the needs of both the athlete and other coaches to receive and forward information. The strength and conditioning practitioner identifies how the role results in working to relay information for the athlete to other support staff and similarly from the support staff through the athlete.

"I think I mean a percentage of the $S$ and $C$ coaches I know are glad to use it and maybe along the lines of instead of having another person in there maybe allowing let's say the sport psych to come in and watch a couple of sessions whereas the $S$ and $C$ coach can deliver the athlete because has got a higher rapport with that athlete. Yeah so it's like a message system you could say"

"We don't have a full time psychologist with the team so again a lot of the bits and pieces we're kind of doing ourselves and we communicate regularly on things we use in training."

The coach perceives that they are able to develop a strong rapport with the athlete which positions them well to receive and relay information from the coach to the athletes and vice versa. Again the ability to develop athlete trust is viewed a crucial skill developed through the career of the strength and conditioning coach (46).

"We sort of communicate back and forth on ways we're going to talk to him and deal with him, he's still a very young lad, he's only 14 so getting across to him that his development is long term."

Similarly, the relay of information from a sport psychologist is a responsibility of a number of the practitioners. It is likely that when delivered by a non-sport psychology-titled professional such as the strength and conditioning practitioner, who has a greater rapport with the athlete, there is an increased receptivity to psychology interventions. This also serves to 
363 illustrate the importance of observing the behavior of the athlete to allow the effective conveying of information to allow other athlete support staff to make appropriate recommendations.

The importance to conveying information is evident however, an additional communicative responsibility has been alluded to. "I think from a conditioning perspective from my role because I am not necessarily involve with selection"

"I am kind of a sounding board for guys; I am a little bit neutral in that respect so they will often engage with me. It's more being a sounding board because they know there will be no repercussions from kind of a neutral person they are talking to almost just talk to them from a common sense perspective potentially play devil's advocate if needed lot of that is just to rationalize what their thoughts are to try you know get them to understand."

The practitioner is removed from the team selection process and as a result, athletes will feel more comfortable sounding thoughts to the strength and conditioning coach. Thus appearing impartial is clearly important in gaining the respect of the athlete and places the practitioner in a valuable position to offer psychological support should the requisite competencies exist.

\section{Sport Psychology interventions}

383 One individual explicitly stated the role the strength and conditioning coach adopts in the absence of a psychologist.

"It's very important, depending on if they have got a sport psychologist that could get into that then use techniques to get them back on the pitch. Then maybe not as much, but a lot of athletes don't tend to have that kind of support, so as an $S$ and $C$ coach it kind of lands on you to be able to provide that psychological information and techniques to get them back onto the pitch. So in that instance I suppose it would be really important."

In the absence of a sport psychologist the strength and conditioning coach has the opportunity to employ psychological intervention techniques. It is evident that the strength and 
393 conditioning coach is required to provide psychological skills in the absence of the sport 394 psychologist. However it is apparent that this is a role adopted in the absence of the psychologist and, depending on perceived competencies, the coach may demonstrate a reluctance to provide psychological skills training should the psychologist be present.

398 In addition to providing the aforementioned emotional support, one strength and conditioning coach related to the requirement of psychological skills to support rounded development of the athlete. you know you're not just there to get them to lift more you're developing an allround athlete and that includes psychological training"

It is clear that the role of the strength and conditioning practitioner is important in creating an athlete that possesses a spectrum of skills in addition to those specific to strength and conditioning. This indicates that the strength and conditioning coach perceives their role to extend beyond that of the traditional physical preparation for sport performance and that they are required to work towards equipping the athletes with psychological skills.

\section{DISCUSSION}

413 The present study revealed that strength and conditioning practitioners considered that the

414 role required psychology orientated responsibilities. Numerous explorations into the

415 responsibilities and behaviors of the strength and conditioner exist (10, 12-15, 44), however 416 they offer limited insight into the use of psychology. The current study contributes to the 417 existing body of knowledge indicating that the coaches' role is dynamic and evolving in 418 which a broad range of adopted role responsibilities are exhibited. It is evident that the role of 
419 the strength and conditioning practitioner is a complex one with various additional

420 responsibilities. Indeed Brooks et al. (5) emphasized that a strength and conditioning

421 practitioner is primarily a coach with responsibilities to provide social, emotional, and

422 physical development.

423

424 A large proportion of the strength and conditioning coaches made reference made to the unique position that the strength and conditioning practitioner holds. There was the indication that the strength and conditioning practitioner often works in an environment which is removed from the immediate team setting often governed by social dynamics and performance related incentives which can often result in conflicts within the team (36). There was the notion that within the team setting, governed by team selection stressors, there is a paucity of athlete-centered attention yet the removed position of the strength and conditioning professional presents an environment in which an athlete-centered approach can be facilitated. With frequent athlete contact, however distinct from other coaching staff, the strength and conditioning coach may be well placed to serve as a mentor and work with the client on an individual basis to foster psychological and physical development detached from the stressors associated with team setting.

437 Experienced strength and conditioning practitioners have been observed to be more readily 438 able to work at an individual level catering for the athlete's physical and psychological 439 development (46). The ability to develop a positive rapport with the client was a prime 440 quality acknowledged by experienced practitioners (46). Indeed, it is likely that when 441 delivered by a non-sport psychology-titled professional, such as the strength and conditioning 442 practitioner, who has a greater rapport with the athlete, there is an increased receptivity to 443 psychology interventions and thus increasing the potential opportunity for administering 
444 psychological interventions. This is likely owing to the stigma associated with seeing the 445 support of psychology tilted professionals $(26,27,47,48,52)$.

447 Through the work of Tod et al. (46), it is apparent that as strength practitioners gain 448 experience, there is also an increased awareness of interpersonal skills in addition to the 449 established training responsibilities of the practitioner. It is important to note that such examples were evident when the practitioner had the opportunity to work on an individual one-to-one basis. Practitioners working within a team setting are responsible for numerous athletes at a given time may not be afforded such an occasion to adopt a mentoring role. In addressing the psychological need of the athlete, the strength and conditioning professional is a valuable asset to the athlete support team. Not least because the need to "manage athletes psychologically" is a significant stressor experienced by elite coaches (36) and the contribution from additional sources could lessen the burden through working collaboratively to address such athlete requirements. The perception existed that the role of other staff was to

458 be working at solely a team level and neglecting individuals within the team. Existing 459 research has identified that a distinguishing factor between experienced and lesser 460 experienced coaches is the ability to build a positive rapport with the client (46). Thus, this potential misperception may account for the strength and conditioning practitioner adopting a mentoring role in which they work on an individual basis with athletes. It is possible that the

463 misperception of the strength and conditioning coach, especially when removed from the 464 team organization, results in them trying to fulfil roles outside of their primary 465 responsibilities.

467 A selection of respondents suggested that they adopt a counselling role in which they were 468 required to address problems lying outside the strength and conditioning environment. It 
469 should be emphasized that predominantly more experienced strength and conditioning 470 coaches suggested such a role. Tod (46) noted that, with increased experience, the coach

471 occasionally assumes a role in which the athlete shares sensitive information. Evidently, there

472 is evidence of role ambiguity with the use of psychological interventions which are unrelated

473 to the specific strength and conditioning objectives. Notwithstanding the integration of

474 diverse roles which have been shown to be an effective characteristic for coaches to acquire 475 in strength and conditioning (46) and North American collegiate athletics (28) the adoption of such responsibilities poses an ethical question. The sport community has questioned the location of the theoretical ethical boundary $(51,53)$. This is pertinent as the appropriate level of qualification and training has been previously queried by Athletic Directors (51).

The role of the strength and conditioning coach is clearly complex in which responsibilities are being adopted that are removed from the physical preparation of athletes. The counselling discipline is specialized and separate from that of psychological skills training and indicates that a selection of practitioners perceive that they are able to use additional so-called softskills (46) whilst there is the misperception that they can offer a service akin to counselling. It is clear that, in addition to the misunderstanding of counselling being merely emotional support rather than as a standalone specialist discipline, there is the temptation to cross role boundaries and practice outside of the competencies of the accredited strength and conditioning professional. This identifies important areas for professional development in positioning referral mechanisms and educating in the ethical boundaries within professions.

491 Sport psychology is a discipline in its own right with the title of Sport and Exercise 492 Psychologist receiving protected status within the United Kingdom (22). Receiving 493 considerable training and assessment to become a certified Sport Psychologist, it is obvious 
494 that there are instances requiring the experience and intervention of appropriately licensed 495 practitioners which go beyond the competencies of the coach $(1,19,32)$. In such instances, 496 the appropriate referral network should be to the psychology-titled professional, as is the case

497 in physiotherapy (23). Assuming the current growth of strength and conditioning as a 498 discipline, an understanding of the ethical boundary and limitations of the practitioners' 499 competency would be an important consideration as would an understanding of appropriate 500 referral networks. Thus, in line with recommendations within physiotherapy (35), it should be 501 clear that without appropriate training a coach should not be expected to apply specialized 502 interventions which would be considered to be responsibility of psychology-titled 503 professionals.

505 There have been steps forward in defining competence and suggesting who is qualified to educate athletes regarding their psychological skills, however whilst it is the responsibility of the psychologist to offer counselling and attend to clinical issues $(1,32)$, the use of

508 psychological performance enhancement skills offers a blurred boundary with questions as to

509 who is qualified to administer such skills (53). This is further exacerbated as no guidelines 510 exist as to the application of mental skills within coaching (53).

512 The requirement to use 'psychological skills' to enhance performance is a role responsibility 513 of strength and conditioning specialists accredited by the NSCA (34) whereas there is little 514 reference made to the use of psychology by other strength and conditioning associations. 515 However, such lack of clarity in the role description is problematic. This is echoed in other 516 disciplines, such as sport coaching, athletic training, and physiotherapy, whereby leading 517 organizations state that particular skill sets should be learned, however do not require the use 518 of skills within the published role responsibilities (53). Conversely, other organizations state 
that only those licensed as psychologists are able to provide psychological support to their athletes (53). However, this would prohibit the support personnel, for example coaching and rehabilitation professionals, with the greatest contact with the athlete from implementing psychological skills (53).

524 Whilst clear definitions must distinguish between psychological skills training, general interpersonal attributes, and clinical skills of counselling, the question is posed as to whether coaches can use mental skills training if they have had no formal training (53). There is an indication that without sufficient training detrimental outcomes may arise and result in negative misconceptions towards psychology. The potential problems associated with untrained professionals approaching mental skills consist of offering a 'canned' approach in which individual differences are neglected, having insufficient range of skills to provide suitable interventions, along with the insufficient awareness of the appropriate time to administer interventions, and lacking the pedagogical knowledge to communicate and rationalize the use of such skills with athletes $(8,21,45)$. Such harmful outcomes would negatively influence the likelihood of applying psychological strategies. Concerning the increasing demand for psychological skills training (49) and the unrealistic view that solely qualified psychology titled professions provide psychological skills (7), with appropriate role clarification, other support staff could be involved with teaching of psychological skills (53).

538 This is evident within athletic training $(4,6,16,50)$, physiotherapy $(2,3,20,23)$, and sport 539 coaching (18). This would be especially important concerning the financial and logistical 540 barriers to employing a psychologist $(24,37)$ resulting in athletes being unable to receive the 541 professional services of a sport psychology consultant. 
543 The present investigation has identified that the strength and conditioning professional is

544 employing psychologically oriented strategies to facilitate athlete growth within, and outside,

545 the strength and conditioning environment. Aside from the work of Tod (46) noting the need

546 for softer skills, detailed exploration has to date focussed only on the perspective of cognitive

547 behavioural interventions to improve performance $(38,39)$. The present work demonstrates

548 that there is also attention focused towards the humanistic perspective in developing a

549 rounded individual with less emphasis on acute cognitive interventions for performance gain.

550 This is a noteworthy observation emanating from the present work and provides support for a

551 valuable strand of practitioner development focussing on humanistic centred approaches and

552 indeed the associated clarification of ethical boundaries associated in the provision of sport

553 psychology support. Thus it is clear that there must be increased focus on both the 554 appropriate use of psychological strategies and also the positioning of referral networks and educational programs to facilitate the inclusion of psychological interventions within the strength and conditioning domain.

\section{PRACTICAL APPLICATIONS}

561 The adopted roles of the strength and conditioning coach appear to be shaped by the position they adopt within the coaching organizational structure. Strength and conditioning coaches have frequent contact with the athlete often away from the pressures associated with team

564 selection (36). This results in the facilitation of a positive report between athlete and

565 practitioner. Thus, the strength and conditioning coach is in a valuable position to promote

566 the use of psychological skills due to the frequency of athlete contact and generation of rapport. Furthermore the unique positioning dictates that, when working within an 
organization, clear communication channels are established between the strength and

conditioning coach, the sport coaches and appropriate specialized disciplines owing to the

endeavour to assess role boundaries with their practice and critically examine whether they

have the requisite qualifications and understanding of the discipline. Coaches would be well

advised to attend continuing professional development events with a focus on the use of and conditioning practitioners would be well advised to upskill in such areas through reflecting on athlete interactions and attending available workshops.

\section{REFERENCES}

1. Andersen MB, Van Raalte JL, and Brewer BW. Sport psychology service delivery: staying ethical while keeping loose. Professional psychology, research and practice 32: 12-18, 2001.

2. Arvinen-Barrow M, Hemmings B, Weigand D, Becker C, and Booth L. Views of chartered physiotherapists on the psychological content of their practice: A follow-up survey in the UK. J Sport Rehabil 16: 111-121, 2007.

3. Arvinen-Barrow M, Penny G, Hemmings B, and Corr S. UK chartered physiotherapists' personal experiences in using psychological interventions with injured athletes: An Interpretative Phenomenological Analysis. Psychol Sport Ex 11:

58-66, 2010.

4. Brewer BW, Jeffers KE, Petitpas AJ, and Vanraalte JL. Perceptions of psychological interventions in the context of sport injury rehabilitation. Sport Psychol 8: 176-188, 1994.

5. Brooks DD, Ziatz D, Johnson B, and Hollander D. Leadership Behavior and Job Responsibilities of NCAA Division 1A Strength and Conditioning Coaches. $J$ Strength Cond Res 14: 483-492, 2000.

6. Cramer JL and Perna FM. Psychology/Counselling: A universal Competency in Athletic Training J Athl Train 35: 458-465, 2000.

7. Danish SJ and Hale B. Toward an understanding of the practice of sport psychology. $J$ Sport Psychol 3: 90-99, 1981.

8. Danish SJ, Petitpas A, and Hale B. Life development interventions for athletes: Life skills though sports. The Counselling Psychologist 21: 352-385, 1993. 
6049 9. Devonport TJ. Perceptions of the contribution of psychology to success in elite

605

606

607

608

609

610

611

612

613

614

615

616

617

618

619

620

621

622

623

624

625

626

627

628

629

630

631

632

633

634

635

636

637

638

639

640

641

642

643

644

645

646

647

648

649

650

651

10. Duehring MD, Feldmann CR, and Ebben WP. Strength and conditioning practices of united states high school strength and conditioning coaches. J Strength Cond Res 23: 2188-2203, 2009.

11. Dunn JGH and Holt NL. Collegiate ice hockey players' perceptions of the delivery of an applied sport psychology program. Sport Psychol 17: 351-368, 2003.

12. Durell DL, Pujol TJ, and Barnes JT. A survey of the scientific data and training methods utilized by collegiate strength and conditioning coaches. J Strength Cond Res 17: 368-373, 2003.

13. Ebben WP and Blackard DO. Strength and conditioning practices of national football league strength and conditioning coaches. J Strength Cond Res 15: 48-58, 2001.

14. Ebben WP, Carroll RM, and Simenz CJ. Strength and conditioning practices of national hockey league strength and conditioning coaches. J Strength Cond Res 18: 889-897, 2004.

15. Ebben WP, Hintz MJ, and Simenz CJ. Strength and conditioning practices of major league baseball strength and conditioning coaches. J Strength Cond Res 19: 538-546, 2005.

16. Ford IW and Gordon S. Perspectives of sport trainers and athletic therapists on the psychological content of their practice and training. J Sport Rehabil 7: 79-94, 1998.

17. Gallo GJ and De Marco GMJ. Self-assessment and modification of a division 1 strength and conditioning coach's instructional behavior. J Strength Cond Res 22: 1228-1235, 2008.

18. Gould D, Dieffenbach K, and Moffett A. Psychological characteristics and their development in Olympic champions. J Appl Sport Psychol 14: 172-204, 2002.

19. Hack B. Qualifications: Education and experience, in: The Sport Psych Handbook. S Murphy, ed. Champaign, Il: Human Kinetics, 2005, pp 293-304.

20. Hamson-Utley JJ, Martin S, and Walters J. Athletic trainers' and physical therapists' perceptions of the effectiveness of psychological skills within sport injury rehabilitation programs. J Athl Train 43: 258-264, 2008.

21. Hardy L, Jones, G. and Gould, D. Understanding psychological preparation for sport: Theory and practice of elite performers. Chichester: Wiley, 1996.

22. http://www.hpc-uk.org/aboutregistration/protectedtitles/. Accessed September/2012.

23. Hemmings B and Povey L. Views of chartered physiotherapists on the psychological content of their practice: a preliminary study in the United Kingdom. Br J Sports Med 36: 61-64, 2002.

24. Kremer PJ and Marchant DB. Reflections and considerations of providing sport psychology sevices with professional football players., in: Science and Football IV. W Spinks, ed. London: Routledge, 2002, pp 294-299.

25. Lincoln YS and Guba EG. Naturalistic Inquiry. London: SAGE Publications, 1985.

26. Linder DE, Brewer BW, Van Raalte JL, and de Lange N. A negative halo for athletes who consult sport psychologists: Replication and extension. J Sport Exerc Psychol 13: 133-148, 1991.

27. Martin SB. High school and college athletes' attitudes toward sport psychology consulting. J Appl Sport Psychol 17: 127-139, 2005.

28. Martinez D, M. Study of the key determining factors for the NCAA division 1 head strength and conditioning coach. J Strength Cond Res 18: 5-18, 2004. 
29. Massey CD, Maneval MW, Phillips J, Vincent J, White G, and Zoeller B. An analysis of teaching and coaching behaviors of elite strength and conditioning coaches. $J$ Strength Cond Res 16: 456-460, 2002.

30. Massey CD, Schwind JJ, Andrews DC, and Maneval MW. An analysis of the job of strength and conditioning coach for football at the division II Level. J Strength Cond Res 23: 2493-2499, 2009.

31. Massey CD, Vincent J, and Maneval M. Job analysis of college division I-A football strength and conditioning coaches. J Strength Cond Res 18: 19-25, 2004.

32. McCann S. Roles: The Sport Psychologist, in: The Sport Psych Handbook. S Murphy, ed. Champaign, Il: Human kinetics, 2005, pp 279-292.

33. Mellalieu S and Shearer D. Mental skills training in strength and conditioning, in: The psychology of stregnth and conditioning. D Tod, D Lavelle, eds. Oxon, UK: Routledge, 2012, pp 1-39.

34. National Strength and Conditioning Association. National Strength and Conditioning Association: Strength and Conditioning Professional Standards and Guidelines. Strength Cond J 31: 14-38, 2009.

35. Ninedek A and Kolt GS. Sport physiotherapists' perceptions of psychological strategies in sport injury rehabilitation. J Sport Rehabil 9: 191-206, 2000.

36. Olusoga P, Butt J, Hays K, and Maynard I. Stress in elite sports coaching: Identifying stressors. J Appl Sport Psychol 21: 442-459, 2009.

37. Pain MA and Harwood CG. Knowledge and perceptions of sport psychology within English soccer. J Sports Sci 22: 813-826, 2004.

38. Radcliffe JN, Comfort P, and Fawcett T. The perception of psychology and the frequency of psychological strategies used by strength and conditioning practitioners. J Strength Cond Res 27: 1136-1146, 2013.

39. Radcliffe JN, Comfort P, and Fawcett T. Psychological Strategies Included by Strength and Conditioning Coaches in Applied Strength and Conditioning. J Strength Cond Res 29: 2641-2654, 2015.

40. Simenz CJ, Dugan CA, and Ebben WP. Strength and conditioning practices of National Basketball Association strength and conditioning coaches. J Strength Cond Res 19: 495-504, 2005.

41. Smith JA. Reflecting on the development of interpretative phenomenological analysis and its contribution to qualitative research in psychology. Qualitative Research in Psychology 1: 39-54, 2004.

42. Smith JA and Eatough V. Interpretative Phenomenological Analysis, in: Research methods in Psychology. GM Breakwell, JA Smith, DB Wright, eds. London: Sage Pulications, 2012.

43. Smith JA and Osborn M. Interpretative Phenomenological Analysis, in: Qualitative Psychology: A practical guide to research methods. JA Smith, ed. Thousand Oaks, CA: Sage Publications Inc., 2003, pp 51-80.

44. Sutherland TM and Wiley JP. Survey of strength and conditioning services for professional athletes in four sports. J Strength Cond Res 11: 266-268, 1997.

45. Tod DA and Anderson M. Success in sport psych: Effective sport psychologists, in: The Sport Psych Handbook. S Murphy, ed. Champaign, Il.: Human Kinetics, 2005, pp 305-314.

46. Tod DA, Bond KA, and Lavallee D. Professional development themes in strength and conditioning coaches. J Strength Cond Res 26: 851-860, 2012.

47. Van Raalte JL, Brewer BW, Brewer DD, and Linder DE. NCAA Division II College Football Players' Perceptions of an Athlete Who Consults a Sport Psychologist. $J$ Sport Exerc Psychol 14: 273-282, 1992. 
48. Van Raalte JL, Brewer BW, Linder DE, and De Lange N. Perceptions of sportoriented professionals: A multidimensional scaling analysis. The Sport Psychologist 4: 228-234, 1990.

49. Weinberg RS and Gould D. Foundations of Sport and Exercise Psychology. Human Kinetics, 2010.

50. Wiese DM, Weiss MR, and Yukelson DP. Sport psychology in the training room: A survey of athletic trainers. Sport Psychol 5: 15-24, 1991.

51. Wilson KA, Gilbert JN, Gilbert WD, and Sailor SR. College athletic directors' perceptions of sport psychology consulting. Sport Psychol 23: 405-424, 2009.

52. Zakrajsek RA, Martin SB, and Zizzi SJ. American high school football coaches' attitudes toward sport psychology consultation and intentions to use sport psychology services. International Journal of Sports Science \& Coaching 6: 461-478, 2011.

53. Zizzi SJ, Blom LC, Watson JC, II, Downey VP, and Geer J. Establishing a hierarchy of psychological skills: coaches', athletic trainers', and psychologists' uses and perceptions of psychological skills training. Athletic Insight: The Online Journal of Sport Psychology 11: unpaginated, 2009. 


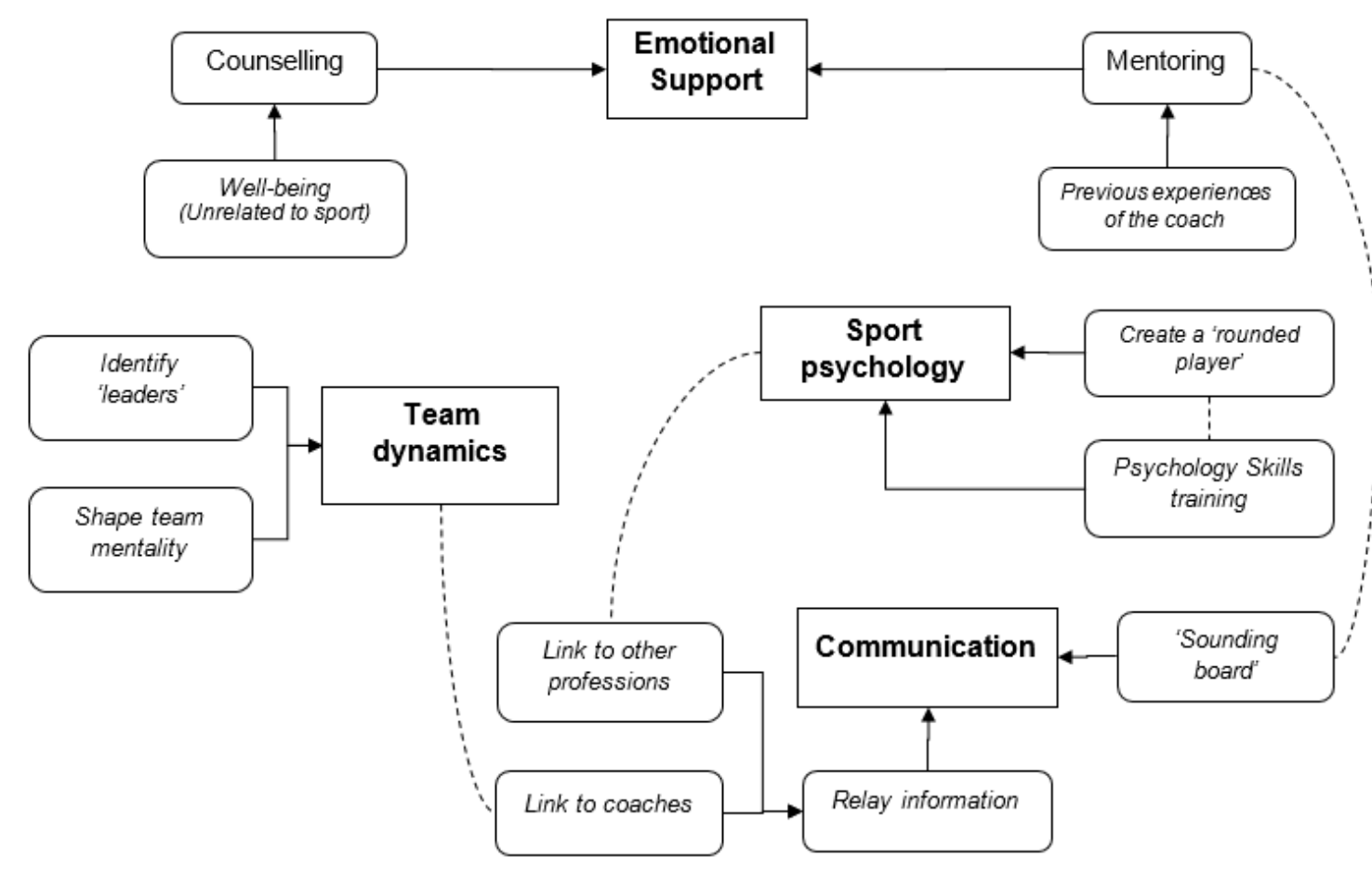

Figure 1. Schematic representation of the complexities of the perceived psychological responsibilities of the Strength and Conditioning specialist. 